\title{
Diagnosis of Non-Malignant Uterine Cervix Pathologies
}

\author{
Denisa Bajraktari $^{1}$, Avenir Balili ${ }^{2}$, Odeta Hoxhaj ${ }^{3}$ \\ ${ }^{1}$ Obstetric Gynecologic Hospital "Queen Geraldine” Tirana, Albania \\ ${ }^{2}$ Faculty of Natural Sciences
}

\begin{abstract}
Identifying premalignant and benign diseases of the cervix and selecting an appropriate treatment path can be challenging. The aim of this study is to describe the role of cytological diagnosis in detection of non-malignant and neoplastic lesions of the cervix in tertiary hospital. This was a hospital-based cross-sectional study on women aged 20-70 years admitted over the period January 20132015 to the Obstetric Gynaecologic University Hospital "Queen Geraldine", in Tirana, Albania. One thousand Pap smears were taken and sent to the department of pathology for analysis. During this study 212 Pap smears were examined in our laboratory. The ages of the subjects ranged from 20 to 68 years, with a mean of $43.8 \pm 14.7$ years. 21 (10\%) smears showed premalignant or malignant changes. The normal cervix varies throughout life, and understanding this transition is key to diagnosis of differences noted on evaluation of the cervix.
\end{abstract}

Keywords: uterine cervix, citologic diagnosis, histologic type

\section{Introduction}

Identifying premalignant and benign diseases of the cervix and selecting an appropriate treatment path can be challenging. Often, benign cervical disease appears malignant and malignant disease can be hidden from view (1). The focus of this chapter is to describe the range of diseases from benign through premalignant diseases of the cervix and describe options for management as well as guidelines that help identify those with potentially more serious or invasive diseases. Cervical lesions range from being visible only with an instrument that augments sight such as a colposcope to gross abnormalities $(2,3)$. Diagnosis and management requires a compilation of visual (including colposcopy or staining), tactile, and laboratory assessments (HPV tests, Papanicolaou smears, cultures, biopsy, etc.). Triage of cervical lesions begins with history and symptomatology. Previous history of any malignancy, particularly those that are prone to metastases, including breast, melanoma, gestational trophoblastic disease, and high-grade malignancies of the gastrointestinal tract or lung, may be a clue that this lesion represents a rare metastasis to the cervical area putting this lesion out of the benign category. Previous history of cervical surgeries, abnormal HPV or Pap smears, uterine polyps, or myoma all help guide the direction of the examination. Lesions characterized by bleeding and discharge immediately raise the possibility of infection and/or malignancy (4). Lesions with local pressure symptoms, for example, bladder pressure or urgency, also raise these two diagnoses. Lesions associated with cramping similar to that associated with cervical dilation with childbirth (with or without discharge) raise the possibility of prolapsing uterine or cervical myomas, polyps, or even malignancies. Classic watery or foul discharge could indicate an invasive malignancy, and a gush of fluid raises the question of tubal disease. Thus, eliciting a good history immediately begins to focus the differential diagnosis for the lesion. The second element of diagnosis is the physical examination $(5,6)$. While a full physical examination is often warranted, the elements of a pelvic examination performed before a directed cervical examination are critical in continuing to delineate the diagnosis. Specifically, groin nodes should be palpated first, because enlargement may point to an unexpected infection or malignancy. The skin of the perineum and the mucosa of the vagina are inspected closely and lesions present in this area (for example, condylomata) again refine the differential further $(7,8)$. Finally, the cervix itself is carefully evaluated in total. If the characteristics of the lesion are unusual, consideration of additional staining (Lugol's or acetic acid) or colposcopic assessment is appropriate to allow better assessment of the nature of the lesion and the blood supply to it. Examination of the cervix with a speculum can be challenging. Availability and use of a wide range of sizes of speculums, as well as rigid sigmoidoscopies for women with long vaginal canals or large size can assist in this evaluation. It is always important to remember to examine the vaginal mucosa in the fornix and throughout the vagina as part of a cervical exam to further elucidate the cause of symptoms, as it may be vaginal rather than cervical in nature $(9,10)$. Furthermore, malignancies can originate or extend to these areas and a complete exam will define the cancer more effectively. The aim of this study is to describe the role of cytological diagnosis in detection of non-malignant and neoplastic lesions of the cervix in tertiary hospital.

\section{Materials and Methods}

This was a hospital-based cross-sectional study on women aged 20-70 years admitted over the period January 20132015 to the Obstetric Gynecologic University Hospital "Queen Geraldine", in Tirana, Albania. One thousand Pap smears were taken and sent to the department of pathology for analysis. Patients presenting with complaints of backache, hypogastric pain, painful sexual intercourse, vaginal discharge, or postcoital bleeding were included in the study. Those having vaginal bleeding other than postcoital and postmenopausal were excluded. History and other relevant information were recorded in a specially designed proforma. Written informed consent was obtained 


\section{International Journal of Science and Research (IJSR) \\ ISSN (Online): 2319-7064 \\ Index Copernicus Value (2013): 6.14 | Impact Factor (2015): 6.391}

from all patients (or the relative) before the smear was taken. This study was in accordance with the Declaration of Helsinki. Before taking the Pap smear we ensured that the patient was not menstruating, had passed 10-20 days of her menstrual cycle, and had not douched or used tampons or vaginal medication for the preceding 24 hours. The samples were smeared on two glass slides and were submitted to the pathology department for examination. The smears were stained using the conventional Papanicolaou technique, in which tinctorial dyes and acids are selectively retained by cells. Unstained cells cannot be visualised under the light microscope. The stains originally chosen by Papanicolau were selected to highlight cytoplasmic keratinisation, which actually has almost nothing to do with the nuclear features that are used to make the diagnosis these days. After staining, the samples were examined by a qualified cytotechnologist and histopathologist under a light microscope. All the smears were classified according to Bethesda system 2001.

\section{Results and Discussion}

During this study 212 Pap smears were examined in our laboratory. The ages of the subjects ranged from 20 to 68 years, with a mean of $43.8 \pm 14.7$ years. $21(10 \%)$ smears showed premalignant or malignant changes. $4(2 \%)$ of specimens were inadequate for cytological examination. (Table 1). The peak incidence of neoplastic gynecological lesions (38.3\%) was found during 50-59 years. Among the 21 cases showing premalignant and malignant lesions, $(50 \%)$ patients were of postmenopausal age, (42\%) patients were of low socioeconomic status, $(23 \%)$ patients had history of early marriage, (62\%) patients had history of multiparity, and $(85 \%)$ patients had complaints of vaginal discharge. Only (18\%) patients had used oral contraceptives; $7 \%$ of patients were smokers; and $5 \%$ of patients had history of abortions. Only $20 \%$ of the women had had a Pap test within the previous 5 years; $80 \%$ said that they had never had this test before. Out of the 21 cases with premalignant and malignant features, there were cases of atypical squamous cells of undetermined significance (10\%), atypical glandular cells of undetermined significance $(5 \%)$, lowgrade squamous cell intraepithelial lesions (45\%), and highgrade squamous cell intraepithelial lesions $(20 \%) .15 \%$ of patients had squamous cell carcinoma and 5\% patients had adenocarcinoma. All these cases were kept under follow-up. These results shows that benign lesions were more common than their malignant ones in our hospital. Similar findings were reported in other studies as well (11-13). However our report is at variance with reports by some researchers from other parts of the world where malignant cervical lesions were more common than benign lesions. The reason for this variation may be partly due to differences in geo-ethnic variation, inadequate cancer register in our locality and the fact that most cancer patients seek alternative medical therapy hence most cancer cases are not reported.

\section{Conclusion}

The normal cervix varies throughout life, and understanding this transition is key to diagnosis of differences noted on evaluation of the cervix. Normal cervical epithelium should be uniformly pale pink and the epithelium thick enough that the vascular pattern is generally obscured. The cervical squamous to glandular transformation zone varies throughout life, but areas of gland openings within squamous metaplastic tissue are expected. Without estrogen, with chemotherapy, and with radiation, the epithelium tends to become atrophic with a loss of the underlying vasculature and a whiter appearance as well as regression of the squamocolumnar junction . If the cervix is erythematous, white in appearance, with prominent vascular patterns, friable, or if the area of transformation is beefy or edematous, these are all findings that require explication $(14,15)$. The Pap test is an effective modality for its diagnosis. To improve the coverage of the Pap test under the National Screening Program, information and awareness should be created about the utility of this important diagnostic modality to reduce the mortality due to cervical carcinoma.

\section{References}

[1] Craig P, Lowe D. Non-neoplastic lesions of the cervix. In: Fox H, Well M, editors. Haines and Taylor Obstetrical and Gynaecological Pathology. 5th ed. Edinburgh: Churchill Livingstone; 2003. p. 273-96.

[2] Munoz N, Bosch FX, de Sanjose S, Herrero R, Castellsague X, Shah KV, et al. Epidemiologic classification of human papilloma virus types associated with cervical cancer. N Engl J Med 2003;348:518-27.

[3] Matos E, Lotia D, Amestoy G, Herrera L, Prince MA, Moreno J, et al. Prevalence of human papillomavirus infection among women in Concordia, Argentina: A population-based study. Sex Transm Dis 2003;30:593-9.

[4] Crum CP, Nucci MR, Lee KR. The cervix. In: Mills SE, Carter D, Greenson JK, Oberman HA, Reuter V, Stoler $\mathrm{MH}$, editors. Sternbergs Diagnostic Surgical Pathology. 47th ed. Vol.3. Philadelphia: Lippincott Williams and Wilkins; 2004 .p.2377-2434.

[5] Ferlay J, Bray F, Pisani P, Parkin DM. IARC Cancer Base No 5. Vol. 10. Lyon: IARC Press; 2004. GLOBOCAN 2002: Cancer incidence, mortality and prevalence worldwide, version 2.0; pp. 1741-52.

[6] Coste J, Cochand-Priollet B, de Cremoux P, Le Gales C, Cartier I, Molinie V, et al. Cross sectional study of conventional cervical smear, monolayer cytology, and human papillomavirus DNA testing for cervical cancer screening. BMJ. 2003;326:733. [PMC free article] [PubMed]

[7] Ronco G, Cuzick J, Pierotti P, Cariaggi MP, Dalla Palma P, Naldoni C, et al. Accuracy of liquid based versus conventional cytology: Overall results of new technologies for cervical cancer screening: Randomised controlled trial. BMJ. 2007;335:28. [PMC free article] [PubMed]

[8] Solomon D, Davey D, Kurman R, Moriarty A, O'Connor D, Prey M, et al. The 2001 Bethesda System: Terminology for reporting results of cervical cytology. JAMA. 2002;287:2114-9. [PubMed]

[9] Coker AL, Eggleston KS, Meyer TE, Luchok K, Das IP. What predicts adherence to follow-up recommendations for abnormal Pap tests among older women? Gynecol Oncol. 2007;105:74-80. [PubMed]

[10] Engelstad LP, Stewart SL, Nguyen BH, Bedeian KL, Rubin MM, Pasick RJ, et al. Abnormal Pap smear 


\section{International Journal of Science and Research (IJSR) \\ ISSN (Online): 2319-7064}

Index Copernicus Value (2013): 6.14 | Impact Factor (2015): 6.391

follow-up in a high-risk population. Cancer Epidemiol Biomarkers Prev. 2001;10:1015-20. [PubMed]

[11] Davey DD, Neal MH, Wilbur DC, Colgan TJ, Styer PE, Mody DR. Bethesda 2001 implementation and reporting rates: 2003 practices of participants in the College of American pathologists interlaboratory comparison program in cervicovaginal cytology. Arch Pathol Lab Med. 2004;128:1224-9. [PubMed]

[12] Davey DD, Woodhouse S, Styer P, Stastny J, Mody D. Atypical epithelial cells and specimen adequacy: Current laboratory practices of participants in the college of American pathologists interlaboratory comparison program in cervicovaginal cytology. Arch Pathol Lab Med. 2000;124:203-11. [PubMed]

[13] Koss L, Melamed M. Koss' diagnostic cytology and its histopathologic bases. Philidelphia: JB Lippincot Company; 2005. Squamous cell carcinoma of the Uterine cervix and related precacerous lesions in Diagnostic cytology of organs; pp. 282-395.

[14] Smith P. Diagnostic cytopathology. 2nd ed. New York: Churchill Livingstone; 2002. Cervical intraepithelial neoplasia and squamous cell carcinoma of the cervix; pp. 721-53.

[15] Koss L, Melamed M. Koss' diagnostic cytology and its histopathologic bases. Philadelphia: JB Lippincot Company; 2005. Adenocarcinoma and related tumors of the uterine cervix in diagnostic cytology of organs; pp. $395-421$.

Table 1: Citological findings in Pap smear

\begin{tabular}{|c|c|c|}
\hline Result & $\mathbf{N}$ & \% \\
\hline Normal & 103 & 49 \\
\hline Non-neoplastic & 84 & 40 \\
\hline Neoplastic & 21 & 10 \\
\hline Inadequate & 4 & 2 \\
\hline Total & 212 & 100.0 \\
\hline
\end{tabular}

